\title{
Mycobacterieel conjunctivaal granuloom bij een Chinese zaagbekeend (Mergus squamatus)
}

\author{
Mycobacterial conjunctival granuloma in a Scaly-sided merganser \\ (Mergus squamatus)
}

\author{
${ }^{1}$ B. Geboers, ${ }^{1}$ A. Garmyn, ${ }^{1}$ T. Hellebuyck, ${ }^{1}$ R. Haesendonck, ${ }^{1}$. Bosseler, ${ }^{1}$ R. Ducatelle \\ ${ }^{1,2}$ G. Antonissen \\ ${ }^{1}$ Vakgroep Pathologie, Bacteriologie en Pluimveeziekten, \\ ${ }^{2}$ Vakgroep Farmacologie, Toxicologie en Biochemie, \\ Faculteit Diergeneeskunde, Universiteit Gent, Salisburylaan 133, B-9820 Merelbeke
}

\section{Gunther.Antonissen@UGent.be}

\section{AMENVATTING}

Een vijf jaar oude, vrouwelijke Chinese zaagbekeend werd aangeboden met een chronische en wederkerende conjunctivitis van het linkeroog. Op klinisch onderzoek werden overvloedige traanvloei en een kazig nodulair letsel vastgesteld ter hoogte van de palpebrale conjunctiva. Bij autopsie werd een kazig, necrotisch beleg waargenomen ter hoogte van de linkerconjunctiva en de infraorbitale sinus, en er waren multipele granulomen in diverse interne organen aanwezig. Histologisch onderzoek toonde granulomateuze splenitis, hepatitis, arteritis, fibrinonecrotiserende enteritis, conjunctivitis en tevens amyloïdose van lever en milt aan. Bacteriologisch en moleculair onderzoek van de conjunctiva bij het levende dier toonde respectievelijk de aanwezigheid van een multiresistente Escherichia coli en Chlamydia psittaci aan. Deze bacteriën bleken van ondergeschikt pathogeen belang. Pre mortem werd echter geen cytologisch onderzoek of ziehlneelsen (ZN)-kleuring op de histologische coupe van het conjunctivabiopt uitgevoerd. Bovendien werden pre mortem geen bijkomende onderzoeken, zoals bloedonderzoek en radiografie, uitgevoerd. De definitieve diagnose van een Mycobacterium avium-infectie ter hoogte van de conjunctiva en de inwendige organen werd pas bevestigd na autopsie door middel van een $\mathrm{ZN}$ kleuring en polymerasekettingreactie (PCR)- analyse. Lokale en systemische behandelingen met antimicrobiële producten, zoals fluoroquinolonen, tetracyclinen en aminoglycosiden, waren niet succesvol.

\section{ABSTRACT}

A five-year-old, female scaly-sided merganser was presented with a chronic recurrent conjunctivitis of the left eye. Physical examination showed a caseous nodular lesion at the palpebral conjunctiva associated with excessive tearing. Necropsy revealed caseous necrotic debris at the left conjunctiva and infra-orbital sinus, but also multiple granuloma in several internal organs. Histological examination showed granulomatous splenitis, hepatitis, arteritis, fibrinonecrotic enteritis and conjunctivitis, and also amyloidosis of liver and spleen. Bacterial and molecular tests of a conjunctival swab in the live animal showed the presence of a multiresistant Escherichia coli strain and Chlamydia psittaci, respectively. These bacteria had only a secondary pathogenic role. No premortem cytological examination or Ziehl-Neelsen (ZN) staining of the histological section of the conjunctiva biopt or additional tests, such as blood test and radiographs, were performed. Finally, a Mycobacterium avium infection of the conjunctiva and internal organs was confirmed following necropsy by ZN staining and PCR analysis. Local and systemic antimicrobial treatments with fluoroquinolones, tetracyclines and aminoglycosides were unsuccessful. 


\section{INLEIDING}

Conjunctivitis is een van de meest voorkomende oogproblemen bij gezelschapsvogels en wordt vaak gekarakteriseerd door een sereuze of seropurulente traanvloei. Differentiaal diagnostisch kan conjunctivitis bij vogels veroorzaakt worden door zowel infectieuze als niet-infectieuze agentia.

Trauma is een van de belangrijkste onderliggende niet-infectieuze oorzaken van conjunctivitis bij roofvogels, maar wordt ook frequent waargenomen bij andere vogelsoorten (Abrams et al., 2002). Daarnaast kan ook de aanwezigheid van een vreemd voorwerp zoals zand of grasaren, chemicaliën zoals ammoniakdampen, tumoren, hypovitaminose $\mathrm{A}$, excessief vederverzorgingsgedrag (vaak door kooigenoot) of anatomische afwijkingen, zoals entropion, aanleiding geven tot conjunctivitis (Abrams et al., 2002; Miles et al., 2006; Souza et al., 2009; Gelatt en Plummer, 2017).

Parasitaire conjunctivitis kan bij vogels onder andere veroorzaakt worden door de nematoden $O x y$ spirura spp. en Thelazia spp., de leverbot Philophthalmus gralli, de protozoa Toxoplasma gondii, Trichomonas spp. en Cryptosporidium spp. en myiasis (Abrams et al., 2002; Dubey, 2002; Elias et al., 2008; Lopez et al., 2010; Church et al., 2013; Dunham et al., 2016). Veel van deze parasieten komen echter zelden voor in West-Europa en infecties worden vaak uitsluitend waargenomen bij in het wild levende dieren of in het wild gevangen dieren.

Een bacteriële infectie is daarentegen de meest voorkomende oorzaak van conjunctivitis bij vogels. De diagnose van bacteriële conjunctivitis wordt bemoeilijkt omdat de normale conjunctivale microbiota bij vogels slechts in beperkte mate onderzocht zijn. Toch worden Mycoplasma gallisepticum en Chlamydia psittaci regelmatig geassocieerd met conjunctivitis bij watervogels (Abrams et al., 2002). In zeldzame gevallen kunnen ook Mycobacterium spp. oorzaak zijn van conjunctivitis bij vogels. Er werden reeds en-

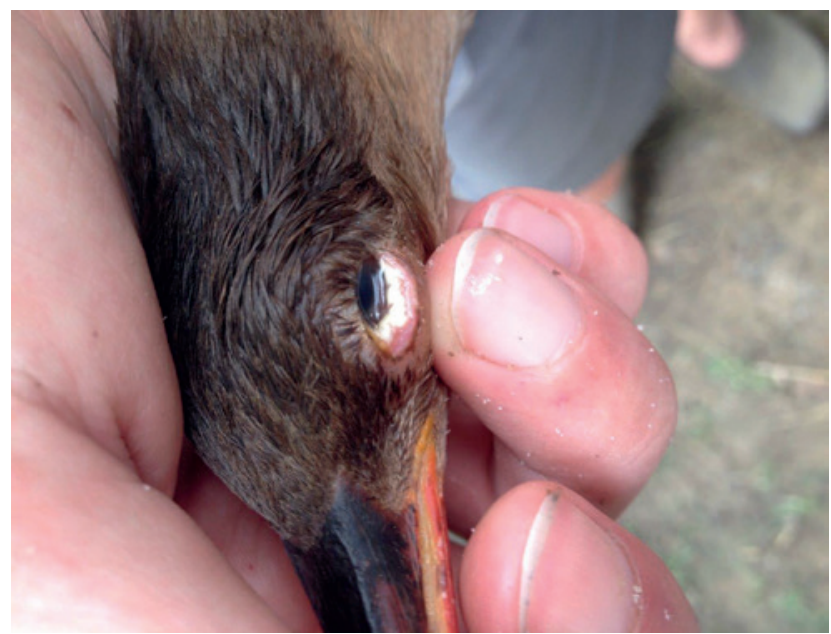

Figuur 1. Kazige, nodulaire letsels ter hoogte van de palpebrale conjunctiva van het linkeroog. kele gevallen gerapporteerd bij struisvogels, emoes, papegaaiachtigen, duiven, zangvogels en roofvogels, veroorzaakt door Mycobacterium avium (M. avium), M. tuberculosis of M. genavense (Washko et al., 1998; Korbel et al., 1997; García et al., 2001; Palmieri et al., 2013). Daarnaast werd ook nog een groot aantal andere bacteriën in verband gebracht met bacteriële conjunctivitis bij vogels, zoals Haemophilus spp., Pasteurella multocida, Actinobacillus spp., Salmonella enterica subsp. arizonae, Escherichia coli, Streptococcus spp. Pseudomonas aeruginosa en Bordetella avium (Zenoble et al., 1983; Devriese et al., 1988; Abrams et al., 2002). Ook infecties met schimmels (Aspergillus fumigatus) en gisten (Candida spp.) komen voor (Crispin en Barnett, 1978; Beckman et al., 1994). Een infectie met het aviaire pokkenvirus gaat meestal gepaard met unilaterale of bilaterale ulceratieve blefaritis met korstvorming, regelmatig gecombineerd met secundaire conjunctivitis en keratitis (Abrams et al., 2002). Herpesvirusinfecties bij vogels kunnen, naast talrijke andere klinische symptomen, ook conjunctivitis veroorzaken (Paulman et al., 2006; Shivaprasad en Phalen, 2012). Tenslotte worden ook nog talrijke andere virale oorzaken vermeld als occasionele oorzaak van conjunctivitis, zoals influenzavirus, paramyxovirus en adenovirus (Abrams et al., 2002).

In deze casus wordt een zeldzaam geval van conjunctivitis bij een eend beschreven geassocieerd met Mycobacterium avium.

\section{CASUÏSTIEK}

Een vijf jaar oude, vrouwelijke Chinese zaagbekeend (Mergus squamatus) van 680 gram werd aangeboden op de Faculteit Diergeneeskunde (UGent) met een unilaterale massa ter hoogte van het onderste linkerooglid. Het dier leefde samen met een mannelijke Chinese zaagbekeend en ongeveer twintig andere eenden van verschillende soorten in een volière van ongeveer $120 \mathrm{~m}^{2}$, waarin vier vijvers aanwezig waren. Het water van deze vijvers werd continu gefilterd en de hokken werden regelmatig schoongemaakt. Het koppel werd na de start van de problemen afgezonderd van de andere dieren in een apart hok bij de eigenaar.

De massa ter hoogte van de conjunctiva werd enkele maanden vóór presentatie reeds opgemerkt door de eigenaar en werd toen succesvol behandeld met een lokale toediening van chlooramfenicol (Chlooramfenicol $1 \%$ + vitamine A oogzalf, Virbac, Barneveld, Nederland) en oxytetracycline oogzalf (Terramycine + polymyxcine B oogzalf, Pfizer, Brussel, België). Een maand vóór het dier op de Faculteit Diergeneeskunde (UGent) aangeboden werd, was de massa teruggekeerd en vertoonde ze een progressieve groei. Behandeling met enrofloxacine (Baytril 10\%, Bayer Animal Health, Diegem, België) per oraal gedurende 
1 week (20 mg/kg lichaamsgewicht (LG), 2 maal per dag (BID)) en ciprofloxacine oogdruppels (TID, ciloxan $3 \mathrm{mg} / \mathrm{mL}$, Alcon, Puurs, België) voorafgaand aan de consultatie gaven geen beterschap. Ook bij het mannelijke dier van het koppel werd reeds enkele dagen overvloedige traanvloei opgemerkt.

Tijdens het algemeen onderzoek van het vrouwelijke dier werden een kazig, nodulair letsel ter hoogte van de palpebrale conjunctiva en overvloedige traanvloei opgemerkt ter hoogte van het linkeroog (Figuur 1). Cytologisch onderzoek van een conjunctivaswab van het linkeroog toonde bij hemacolorkleuring een overvloedige aanwezigheid van bacteriën, maar geen gisten of schimmelhyfen. Bacteriologisch onderzoek van een conjunctivaswab toonde een multiresistente Escherichia coli aan. Op basis van dit antibiogram werd de behandeling aangepast naar gentamycine-ooggel (TID, Clinagel-Vet, Ecupahar, Oostkamp, België). De eigenaar werd geadviseerd ook het mannelijke dier te behandelen.

Zeven dagen later was er geen beterschap bij het vrouwelijke dier. Bovendien was het vermagerd (LG $580 \mathrm{~g}$ ) en apathisch. Bij het mannelijke dier (LG 800g) werd wel beterschap opgemerkt. Omdat de behandeling niet succesvol was, werden er bijkomende diagnostische testen uitgevoerd. De PCR-test uitgevoerd op de conjunctivaswab voor Chlamydia psittaci, gaf een positief resultaat. De behandeling werd op basis van de resultaten van de PCR-test aangepast naar oxytetracycline-oogzalf (TID-QID, Terramycine + polymyxcine B oogzalf) en doxycycline per oraal (50 $\mathrm{mg} / \mathrm{kg}$ LG, BID, Ronaxan 100mg, Merial, Diegem, België).

$\mathrm{Na}$ veertien dagen behandeling bleek de conjunctivaalzak echter opnieuw gevuld met een kazige substantie. Onder gasanesthesie (isofluraan + zuurstof) werd vervolgens een biopt genomen van de massa en van de conjunctiva voor verder histologisch onderzoek. Intraoperatief werd eveneens zoveel mogelijk etter weg gecuretteerd. Het histologisch onderzoek (hematoxyline en eosine (HE)- kleuring) van dit biopt toonde necrotisch weefsel aan met een uitgesproken infiltratie van heterofielen en lymfocyten. Gramkleuring toonde enkel groepjes staafvormige gramnegatieve bacteriën aan. De periodic acid-schiff (PAS)-kleuring was negatief voor schimmelhyfen. De algemene toestand van het vrouwelijke dier ging achteruit, gekenmerkt door lethargie en milde diarree. Enkele dagen later is het dier gestorven. Bij autopsie bleek de eend cachectisch (LG 595 g). De conjunctiva van het linkeroog was gezwollen en op de mucosa van het ooglid was een kazig/necrotisch beleg aanwezig. De linker infraorbitaal sinus was ook gevuld met die substantie. De dunne darm was gevuld met gas en vertoonde vaatinjecties. Het laatste deel van de dunne darm was sterk hemorragisch en necrotisch. De darmlussen waren onderling verkleefd. De longen waren gestuwd en oedemateus. Er was ook één granuloom aanwezig in de longen. De luchtzakken waren troebel en bevatten fibrineus exsudaat. Op de lever

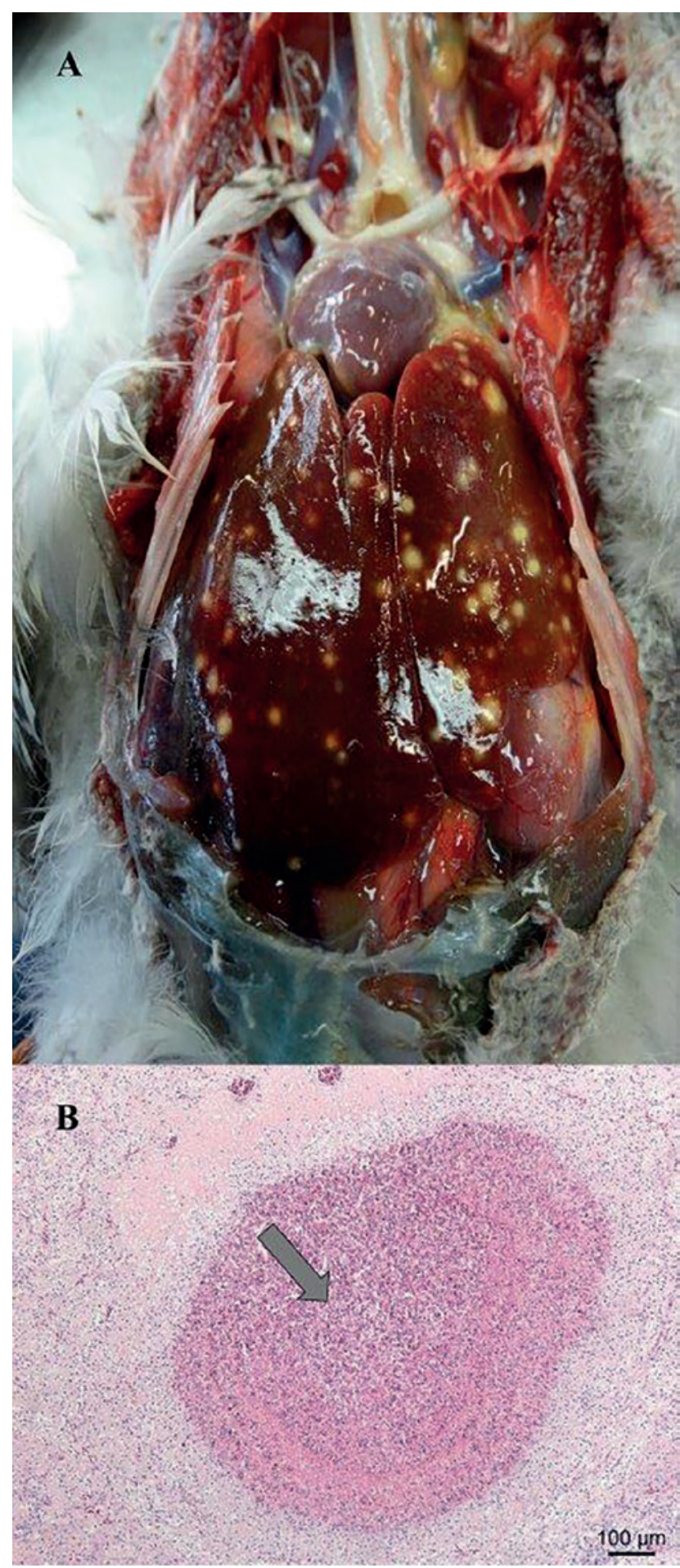

Figuur 2A. Multifocale, granulomateuze letsels in de lever. $B$. Histologische afbeelding (HE-kleuring) van de lever gekarakteriseerd door de aanwezigheid van een granuloom (pijl) met accumulatie van fibrinonecrotisch materiaal met rondom gedegenereerde heterofielen, macrofagen en lymfocyten.

waren multifocale granulomateuze letsels en necrosehaardjes zichtbaar (Figuur 2). In de milt waren eveneens twee granulomateuze letsels te zien. Er werd ook flebitis van de linker vena jugularis opgemerkt.

Op cytologisch onderzoek (hemacolorkleuring) vertoonden de longen en nieren een ontstekingsbeeld, 
voornamelijk gekarakteriseerd door een infiltratie van heterofielen maar ook van macrofagen en enkele lymfocyten. De lever vertoonde eveneens een ontstekingsbeeld en multifocale, blauwe, bolvormige structuren die suggestief waren voor Aspergillus-sporen. Mycologisch onderzoek was echter negatief. Ook in de milt werd er op het cytologisch onderzoek een ontstekingsbeeld waargenomen en was er massale aanwezigheid van gekleurde staafvormige bacteriën te zien. Cytologisch onderzoek van de inhoud van de dunne darm toonde blauwe, bolvormige structuren en een polybacteriële flora aan. Natief onderzoek van de inhoud van de dunne darm en caeca was negatief voor endoparasieten.

Er werd een histologisch onderzoek uitgevoerd van het ooglid (Figuur 3A), de lever, milt, darm, vena jugularis en de longen. Op HE-kleuring vertoonde de lever diffuus sterke atrofie van de leverbalkjes, accumulatie van een grote hoeveelheid homogeen, acellulair, eosinofiel materiaal (amyloïd) in de ruimte van Disse en verscheidene grote granulomen. Aan de mucosale zijde van het ooglid was er een uitgesproken ulceratie met een dikke serocellulaire korst op, die veel fibrine, gedegenereerde heterofielen en grote aantallen bacteriën (zeer kleine coccobacillen) bevatte. Meer heterofielen bevonden zich in de omgevende submucosa. In de milt waren multipele grote granulomen te zien. Rondom de sinusoïden was er amyloïd aanwezig.

In het darmlumen was een fibrineus pseudomembraan aanwezig waarin heterofielen zaten. De submucosa en het mesenterium waren diffuus oedemateus met een exsudaat van fibrine en heterofielen. In het lumen van de vena jugularis was een grote accumulatie van fibrinonecrotisch materiaal aanwezig met vele, zeer kleine, bacteriële kolonies. Rondom dit fibrinonecrotisch materiaal bevonden zich gedegenereerde heterofielen, macrofagen en lymfocyten. Talrijke confluente granulomen waren aanwezig in de longen, die de normale architectuur van het orgaan onherkenbaar maakten. De ZN-kleuring toonde aan dat er massaal veel zuurvaste bacteriën aanwezig waren in en rondom de granulomen (Figuur 3B). Histologisch onderzoek toonde aldus granulomateuze splenitis, hepatitis, arteritis, fibrinonecrotiserende enteritis, conjunctivitis, amyloïdose van lever en milt en een mycobacteriuminfectie van de conjunctiva, longen, lever en milt.

Een 16S ribosomaal RNA-gen gebaseerde PCRtest en sequenering (Tropisch Instituut, Antwerpen, België) toonden de aanwezigheid van Mycobacterium avium in de lever en conjunctiva aan.

\section{DISCUSSIE}

In deze casuïstiek wordt een geval beschreven van mycobacteriose bij een Chinese zaagbekeend die klinisch gekarakteriseerd wordt door de aanwezigheid van een palpebraal conjunctivaal granuloom, granulomateuze septicemie, lethargie en vermageren.

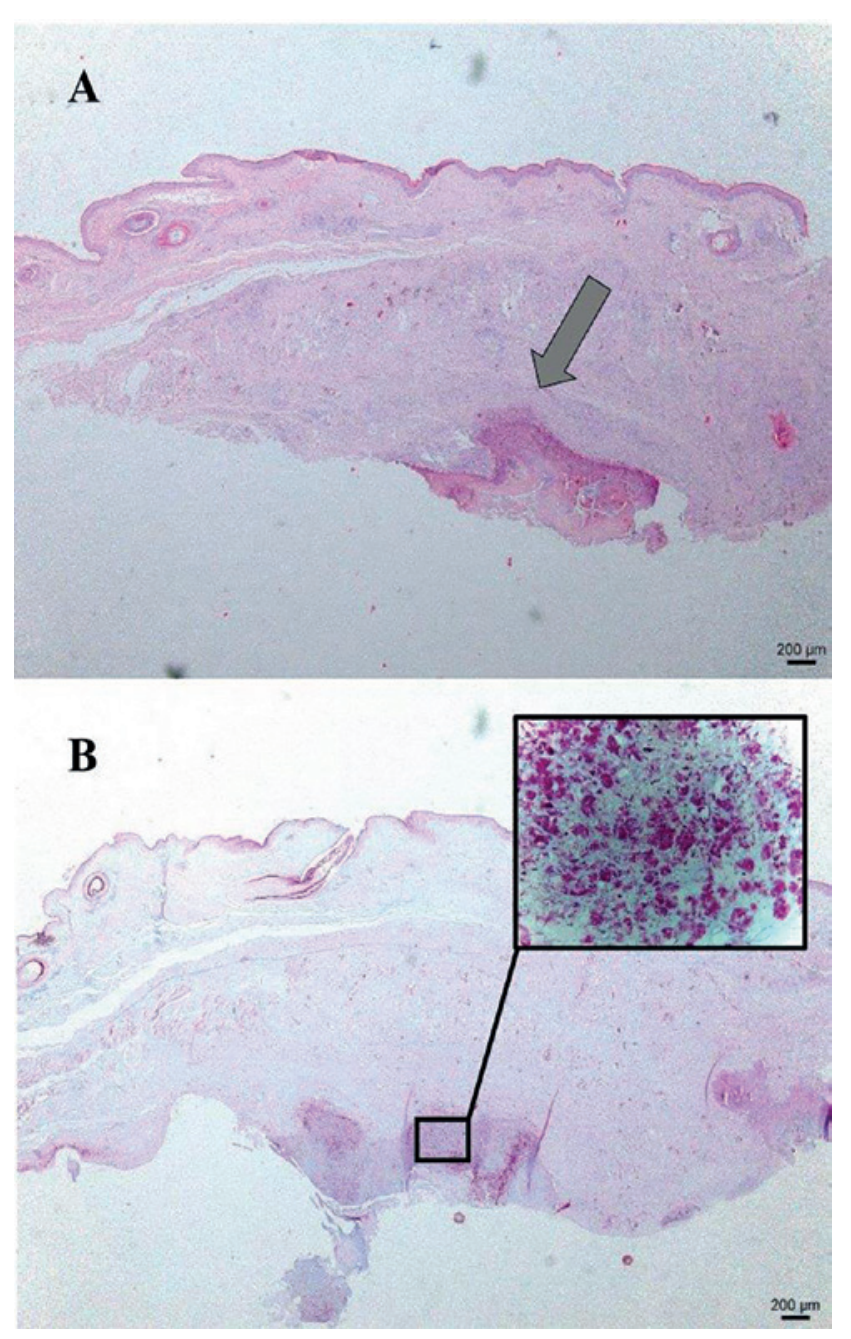

Figuur 3A. Granuloom (pijl) ter hoogte van de conjunctiva met accumulatie van fibrinonecrotisch materiaal (HE-kleuring). B. De ziehl-neelsenkleuring toont de massale aanwezigheid van zuurvaste bacteriën in en rond de granulomen aan.

Uitwendige letsels komen zelden voor bij mycobacteriose bij vogels. De enige afwijkingen die op klinisch onderzoek vaak vastgesteld worden, zijn vermageren met duidelijke atrofie van de pectorale spieren en het afnemen van de subcutane vetreserves (VanDerHeyden, 1997a; Shivaprasad en Palmieri, 2012). In een retrospectieve studie bij Psittaciformen werd vermageren bij 36,4\% van de gevallen vastgesteld (Palmieri et al., 2013). Uitzonderlijk worden kleine nodulen in de huid waargenomen van enkele millimeters tot $1 \mathrm{~cm}$ groot, voornamelijk ter hoogte van de kop, hals of nek, maar soms ook ter hoogte van poten, vleugels, abdomen en rug. Hiernaast worden soms, zoals in dit geval, ook letsels aan de ogen waargenomen, zoals protrusie van één of beide ogen ten gevolge van een retrobulair granuloom, keratitis en kazige nodulen ter hoogte van de palpebrale en bulbaire conjunctiva, de ooghoek en het derde ooglid (Shivaprasad en Palmieri, 2012). In een studie van Palmieri et al. (2013) werden gezwollen oogleden slechts bij 4,7\% van de gevallen van mycobacteriose bij papegaaiachtigen waargenomen. De macroscopische bevindingen bij 
autopsie van de eend in de huidige casus, zoals kazige granulomen en spekachtige letsels ter hoogte van verschillende organen, zijn karakteristiek voor mycobacteriuminfectie (VanDerHeyden, 1997a; Shivaprasad en Palmieri, 2012). De waargenomen amyloidose van de lever is ook een typische bevinding bij chronische inflammatoire ziekten zoals mycobacteriose. Echter, aangezien Anseriformen zoals eenden een genetische predispositie hebben voor de ontwikkeling van amyloïdose, kan deze simultane bevinding ook toevallig zijn (Shivaprasad en Palmieri, 2012).

Omdat uitwendige letsels en pathognomonische klinische symptomen vaak ontbreken, is de ante-mortemdiagnose van mycobacteriose bij vogels moeilijk. Biochemisch bloedonderzoek toont soms milde aspecifieke afwijkingen aan van de leverenzymen en galzuren secundair aan diffuse weefselschade. Daarnaast is op hematologisch onderzoek vaak polychromasie, al dan niet samengaand met anemie waar te nemen. Bij sommige vogels is leucocytose aanwezig gekarakteriseerd door heterofilie, monocytose en lymfocytose (VanDerHeyden, 1997a). Op het cytologisch onderzoek werd in de lever en longen van de eend van de voorliggende casus ook een massale infiltratie van heterofielen, macrofagen en lymfocyten waargenomen. Een $\mathrm{ZN}-k$ leuring van de mest kan de aanwezigheid van zuurvaste bacteriën bij de intestinale vorm van mycobacteriose aantonen maar zelden bij andere vormen (VanDerHeyden, 1997a; Shivaprasad en Palmieri, 2012; Palmieri et al., 2013). Bovendien is de uitscheiding van de bacterie intermitterend. Radiografisch onderzoek kan de aanwezigheid van granulomen in de longen of de coeloomholte aantonen. Andere niet-specifieke bevindingen die waargenomen kunnen worden zijn hepatosplenomegalie, tympanie en verhoogde botdichtheid van het endost (VanDerHeyden, 1997a). Radiografisch onderzoek helpt de inwendige letsels te lokaliseren voor eventuele biopsie. Endoscopisch onderzoek van de coeloomholte is de beste methode om de nodige stalen te verzamelen van organen voor een definitieve diagnose. Eventueel kan een leverbiopt ook transcutaan of via coeliotomie genomen worden (VanDerHeyden, 1997a). Mycobacterium-granulomen zijn typisch wit tot bruin en rond van vorm, in tegenstelling tot aspergillose granulomen die vaak meer schijfvormig zijn. In de differentiaaldiagnose moet ook rekening gehouden worden met andere bacteriële granulomen (bijvoorbeeld ten gevolge van salmonellose, rodentiose of coligranulomatose) en abdominale tumoren, zoals lymfoma's. Een biopt dient genomen te worden voor verder onderzoek. Voor het cytologisch of histologisch onderzoek kan gebruik gemaakt worden van een standaardkleuring (bijvoorbeeld HE-kleuring) of een ZN-kleuring (Shivaprasad en Palmieri, 2012). In tegenstelling tot op histologisch onderzoek zijn mycobacteriën in de praktijk vaak te herkennen op cytologisch onderzoek als nietkleurbare, staafvormige bacteriën op een standaardkleuring. In de huidige casus werd echter geen cyto- logisch onderzoek of ZN-kleuring op de histologische coupe van het biopt uitgevoerd. Er werden wel overvloedig gramnegatieve bacteriën waargenomen, vermoedelijk secundaire multiresistente $E$. coli, en geen schimmels. De definitieve diagnose kon in deze casus pas gesteld worden op basis van ZN-kleuring en PCR van de aangetaste organen na autopsie. Serologische testen, zoals de snelle draagglas-agglutinatietest en ELISA, zijn sterk diersoort-gerelateerd en zijn weinig specifiek, wat resulteert in veel valspositieve resultaten (Cromie et al., 1993; Amador et al., 2010). Bij een positieve tuberculinehuidtest of mantouxtest, waarbij een opgezuiverd, met hitte behandeld eiwitderivaat van M. avium of $M$. tuberculosis $(0,05-0,1 \mathrm{~mL}, 2000$ IU) intradermaal in de kinlellen wordt geïnjecteerd, ziet men na 48 uur een oedemateuze zwelling of een kleine nodule ter hoogte van de injectieplaats. Deze test is diagnostisch bij pluimvee. De werkzaamheid bij gezelschapsvogels is echter onbekend. Bovendien ontbreken dergelijke huidaanhangsels bij vele vogelsoorten (Fulton en Sanchez, 2008). De diagnose kan bevestigd worden door bacteriecultuur, maar de kiem groeit traag (VanDerHeyden, 1997a), waardoor de voorkeur naar moleculaire technieken gaat.

In geval van mycobacteriose wordt meestal geen behandeling ingesteld omwille van het zoönotische belang, de kostprijs en de therapieduur (12-18 maanden). Bovendien zijn er slechts weinig farmacokinetische en farmacodynamische gegevens bekend over het gebruik van antimycobacteriële geneesmiddelen bij vogels. De mycobacterie buitenmembraan bestaat uit een dikke hydrofobe barrière, wat de werking van hydrofiele antimicrobiële producten, zoals fluoroquinolonen, macroliden en aminoglycosiden beperkt. Uit empirisch onderzoek is gebleken dat M. avium- of $M$. genavense-infecties bij gezelschapsvogels behandeld kunnen worden met rifampicine, rifabutine, ethambutol, clofaziminine, ciprofloxacine, enrofloxacine, doxycycline, streptomycine, amikacine, azitromycine of claritromycine (VanDerHeyden, 1997b). Behandeling met fluoroquinolonen, tetracyclinen of aminoglycosiden gaf in deze casus geen verbetering. Vaak wordt er echter gebruik gemaakt van een combinatietherapie met bijvoorbeeld initieel rifabutine $(56 \mathrm{mg} / \mathrm{kg} \mathrm{LG})$ en ethambutol (56-85 mg/kg LG). Later kan daar azitromycine $(43 \mathrm{mg} / \mathrm{kg} \mathrm{LG})$ of claritromycine $(85 \mathrm{mg} / \mathrm{kg}$ LG) aan toegevoegd worden. Bij vogels die slecht reageren op deze therapie kunnen nog fluoroquinolone, aminoglycoside en/of clofazimine (6-12 mg/ $\mathrm{kg} \mathrm{LG)} \mathrm{toegevoegd} \mathrm{worden} \mathrm{(VanDerHeyden,} \mathrm{1997b).}$ Vanuit het standpunt van verantwoord gebruik van antibiotica in de diergeneeskunde en het zoönotisch aspect van mycobacteriose zou het gebruik van dergelijke behandelingsprotocollen beperkt moeten worden. Bij een uitbraak worden geïnfecteerde dieren beter geëuthanaseerd. De omgeving, voornamelijk de bodem en bodembedekking, vormt echter de meest belangrijke bron van infectie. Omdat de bacterie tot meer dan vier jaar lang kan overleven in de omge- 
ving, is het frequent verwijderen van uitwerpselen en bodembedekking van primordiaal belang in de aanpak van de infectie (Fulton en Sanchez, 2008). Het is sterk aan te raden om gedurende meerdere jaren geen vogels te huisvesten in een besmette omgeving.

De aanwezigheid van C. psittaci ter hoogte van de conjunctiva bevestigd met PCR in de huidige casuïstiek, wijst niet noodzakelijk op een oorzakelijk verband met de waargenomen symptomen. Infecties met $C$. psittaci bij eenden verlopen vaak asymptomatisch, maar via massale fecale uitscheiding kunnen deze dieren de omgeving, inclusief het vijverwater, sterk besmetten (Gorham en Lee, 2016). C. psittaciinfecties worden meestal behandeld met doxycyline, chloortetracycline of enrofloxacine (Vanrompay et al., 1995; Perelman et al., 2013). Desondanks was er in deze casus weinig reactie op de antimicrobiële behandeling van $C$. psittaci en $E$. coli. Door het obligate intracellulaire voorkomen van chlamydia is de overdracht van antimicrobiële resistentiegenen beperkt. Antimicrobiële resistentie bij C. psittaci is nog onbekend. Wel werd tetracyclineresistentie reeds vastgesteld bij Chlamydia suis (Dugan et al., 2004; Joseph et al., 2016). In de voorliggende casuïstiek behoorde de geïsoleerde multiresistente $E$. coli tot de normale conjunctivale microbiota en/of was eerder van secundair pathogeen belang (Chalmers et al.,1984; Abrams et al., 2002).

Uit deze casus kan geconcludeerd worden dat mycobacteriose dient opgenomen te worden in de differentiaaldiagnose van chronische of terugkerende conjunctivitis bij eenden. Bijkomende testen, zoals ZN-kleuring en/of PCR van het aangetaste ooglid, ter detectie van een infectie met mycobacteriën zijn dan ook te adviseren. Daarnaast kunnen radiografie en/of endoscopie uitsluitsel geven over de eventuele aanwezigheid van granulomen in organen.

\section{REFERENTIES}

Abrams, G.A., Paul-Murphy, J., Murphy, C.J. (2002). Conjunctivitis in birds. Veterinary Clinics of North America: Exotic Animal Practice 5, 287-309.

Amador, E., Lloret, L., Castillo, A.I., Lopez, Y. (2010). Identification of immunogenic proteins of Mycobacterium avium with diagnostic potential. International Journal of Infectious Diseases 14, 129.

Beckman, B. J., Howe, C. W., Trampel, D. W., DeBey, M. C., Richard, J. L., Niyo, Y. (1994). Aspergillus fumigatus keratitis with intraocular invasion in 15-day-old chicks. Avian Diseases 38, 660-665.

Church, M. L., Barrett, P. M., Swenson, J., Kinsella, J. M., Tkach, V. V. (2013). Outbreak of Philophthalmus gralli in four greater rheas (Rhea americana). Veterinary Ophthalmology 16, 65-72.

Crispin, S.M., Barnett, K.C. (1978). Ocular candidiasis in ornamental ducks. Avian Pathology 7, 49-59.

Cromie, R.L., Brown, M.J., Forbes, N.A., Morgan, J., Stanford, J.L. (1993) A comparison and evaluation of tech- niques for diagnosis of avian tuberculosis in wildfowl. Avian Diseases 22, 617-630.

Devriese, L. A., Viaene, N., Uyttebroek, E., Froyman, R., Hommez, J. (1988). Three cases of infection by haemophilus-like bacteria in psittacines. Avian Pathology 17, 741-744.

Dubey, J. P. (2002). A review of toxoplasmosis in wild birds. Veterinary Parasitology 106, 121-153.

Dugan, J., Rockey, D. D., Jones, L., Andersen, A. A. (2004). Tetracycline resistance in Chlamydia suis mediated by genomic islands inserted into the chlamydial inv-like gene. Antimicrobial Agents Chemotherapy 48, 3989-3995.

Dunham, N. R., Reed, S., Rollins, D., Kendall, R. J. (2016). Oxyspirura petrowi infection leads to pathological consequences in Northern bobwhite (Colinus virginianus). International Journal for Parasitology: Parasites and Wildlife 5, 273-276.

Elias, R., Mamani, J., Hermoza, C., Kinsella, J. (2008). First report of thelaziosis (Thelazia anolabiata) in an Andean Cock of the Rock (Rupicola peruviana) from Peru. Veterinary Parasitology 158, 382-383.

Fulton, R.M., Sanchez, S. (2008). Tuberculosis.” In: Saif Y. M., Fadly, A.M., Glisson, J.R., McDougald, L.R., Nolan, L.K., Swayne, D.E. (editors). Diseases of Poultry. Blackwell Publishing, Ames, IO, USA, 940-951.

García, A., LeClear, C.T., Gaskin, J.M. (2001). Mycobacterium avium infection in an ostrich (Struthio camelus). Journal of Zoo and Wildlife Medicine 32, 96-100.

Gelatt, K.N., Plummer, C.E. (2017). Ophthalmology in exotic pets. In: Gelatt, K.N., Plummer, C.E. (editors). Color Atlas of Veterinary Ophthalmology. John Wiley \& Sons, Ames, IO, USA, 337-350.

Gorham, T. J., Lee, J. (2016). Pathogen loading from Canada geese faeces in freshwater: Potential risks to human health through recreational water exposure. Zoonoses and Public Health 63, 177-190.

Joseph, S. J., Marti, H., Didelot, X., Read, T. D., Dean, D. (2016). Tetracycline selective pressure and homologous recombination shape the evolution of Chlamydia suis: a recently identified zoonotic pathogen. Genome Biology and Evolution 8, 2613-2623.

Korbel, R., Schäffer, E.H., Ravelhofer, K., Kösters, J. (1997). Okulare Manifestationen von Mykobakteriosen bei Vögeln. Tierärztliche Praxis 25, 552-558.

Lopez, R. A., Ramis, A., Martín-Vázquez, S., Gomez-Couso, H., Ares-Mazás, E., Caccio, S. M., Leiva, M., Darwich, L. (2010). Cryptosporidium baileyi infection associated with an outbreak of ocular and respiratory disease in otus owls (Otus scops) in a rehabilitation centre. Avian Pathology 39, 171-176.

Miles, D.M., Miller, W.W., Branton, S.L., Maslin, W.R., Lott, B.D. (2006) Ocular responses to ammonia in broiler chickens. Avian Diseases 50, 45-49.

Palmieri, C., Roy, P., Dhillon, A.S., Shivaprasad, H.L. (2013). Avian mycobacteriosis in Psittacines: a retrospective study of 123 cases. Journal of Comparative Pathology 148, 126-138.

Paulman, A., Lichtensteiger, C. A., Kohrt, L. J. (2006). Outbreak of herpesviral conjunctivitis and respiratory disease in gouldian finches. Veterinary Pathology 43, 963-970.

Perelman, B., Mechani, S., Perl, S., Lublin, A. (2013). The role of Chlamydia psittaci in outbreaks of blepharo-con- 
junctivitis in chickens and ostriches: clinical and laboratory findings. Israel Journal of Veterinary Medicine 68, 3.

Shivaprasad, H. L., Phalen, D. N. (2012). A novel herpesvirus associated with respiratory disease in Bourke's parrots (Neopsephotus bourkii). Avian Pathology 41, 531539.

Shivaprasad, H.L., Palmieri, C. (2012). Pathology of mycobacteriosis in birds. Veterinary Clinics of North America: Exotic Animals 15, 41-55.

Souza, M.J., Johnstone-McLean, N.S., Ward, D., Newkirk, K. (2009) Conjunctival xanthoma in a blue and gold macaw (Ara ararauna). Veterinary Ophthalmology 12, 5355.

VanDerHeyden, N. (1997a). Clinical manifestations of mycobacteriosis in pet birds. Seminars in Avian and Exotic Pet Medicine 6, 18-24.
VanDerHeyden, N. (1997b). New strategies in the treatment of avian mycobacteriosis. Seminars in Avian and Exotic Pet Medicine 6, 25-33.

Vanrompay, D., Ducatelle, R., Haesebrouck, F. (1995). Chlamydia psittaci infections: a review with emphasis on avian chlamydiosis. Veterinary Microbiology 45, 93-119.

Washko, R.M., Hoefer, H., Kiehn, T.E., Armstrong, D., Dorsinville G., Frieden, T.R. (1998). Mycobacterium tuberculosis infection in a green-winged macaw (Ara chloroptera): Report with public health implications. Journal of Clinical Microbiology 36, 1101-1102.

Zenoble, R.D., Griffith, R.W., Club, S.L. (1983). Survey of bacteriologic flora of conjunctiva and cornea in healthy psittacine birds. American Journal of Veterinary Research 44, 1966-1967.

\section{DIEREN TREUREN OM HUN DODE SOORTGENOTEN}

'Ervaren olifantenexperts zijn het er over eens dat olifanten over een basisconcept van de dood beschikken. Net zoals wij het lichaam van een dood mens of een menselijk skelet herkennen, herkennen olifanten karkassen en skeletten van hun eigen soort. Ze ruiken aan de beenderen van hun doden, zelfs aan oude door de zon gebleekte botten, en ze strelen ze met hun slurf. Wanneer een olifant net gestorven is, raken andere olifanten vaak om beurten het lijk met hun achterpoten aan, bedekken het lichaam vervolgens met zand en stokken en houden de wacht. Intrigerend genoeg deden ze hetzelfde met lichamen van mensen die ze dood hebben gevonden, of die ze zelf hebben gedood. Chimpansees, gorilla's, sommige kraaiachtigen en dolfijnen brengen ook enige tijd met hun doden door, maar de meeste soorten in het algemeen niet.'

Iets ingekort overgenomen uit Morell V. (2013). Hoe Dieren Denken. Uitgeverij Balans, Amsterdam, p. 175. Oorspronkelijke titel: Animal Wise.

Luc Devriese 